\title{
Determination of the Loads on the Steering Module of the Push-the-Bit Rotary Steerable System in the Context of Its Reliability
}

\author{
Vitaly ZHIRONKIN ${ }^{1}$, Anton EPIKHIN ${ }^{2}$, Denis NOVOSELTSEV ${ }^{3}$ and Michal CEHLÁR ${ }^{4}$
}

Authors' affiliations and addresses:

${ }^{1}$ National Research Tomsk Polytechnic

University, 63405030 Lenina st., Tomsk, Russia e-mail: vsz14@tpu.ru

${ }^{2}$ National Research Tomsk Polytechnic University, 63405030 Lenina st., Tomsk, Russia e-mail: epikhin@tpu.ru

${ }^{3}$ Tomsk Branch of JSC "SSK",634009 Sovpartshkolny lane 2, Tomsk, Russia e-mail: NovoselcevDI@tf.sibserv.com

${ }^{4}$ Technical University of Košice, 04200 Letná 9, Košice, Slovakia

e-mail: michal.cehlar@tuke.sk

\section{*Correspondence:}

Vitaly Zhironkin, National Research Tomsk Polytechnic University, 63405030 Lenina st., Tomsk, Russia

e-mail:vsz14@tpu.ru

How to cite this article:

Zhironkin, V., Epikhin, A., Novoseltsev, D. and Cehlár, M. (2020). Determination of the Loads on the Steering Module of the Push-the-Bit Rotary Steerable System in the Context of Its Reliability. Acta Montanistica Slovaca, Volume 25 (3), 393-405

DOI:

https://doi.org/10.46544/AMS.v25i3.11

\begin{abstract}
The paper deals with an original approach to the study of loads on elements of a bias unit of the push-the-bit rotary steerable system as a specific factor of system reliability, which becomes especially important as the share of the development of unconventional oil fields grows. It is a high-cost process that increases requirements for the reliability of drilling equipment. The basic principle of the proposed idea is the representation of the module of a rotary steerable system as an absolutely elastic rod, which is acted upon by a complex of forces arising from the directional and horizontal undulating well profiles. Under certain conditions, the interaction of these forces, resulting in the load on the steering pad, can approach the maximum values, which increases the risk of failure of the entire bottom-hole assembly of the rotary controlled system. This article substantiates the phenomenon of multiple load drops on the steering pad in the process of changing the drilling interval of directional wells from ascending to descending when drilling a horizontal section with a wave profile. In this regard, based on the analysis of the weight on bit effect on the steering pad load, it is recommended to adjust the drilling mode to reduce the risk of failure of the push-the-bit rotary steerable system. The advantage of the presented method, along with computational efficiency and visualization, is applicability for load analysis not only for push-thebit rotary steerable systems but also for the most modern combined systems. Attention is also paid to the possibility of reducing the load on the steering pedals by changing the concentration of the lubricant in the drilling mud upon the condition of follow-on research on the effect of these changes on the rotary steerable systems operation.
\end{abstract}

\section{Keywords}

drilling, rotary steerable system, "push-the-bit", steering pad, load, reliability. 


\section{Introduction}

The increase in hydrocarbon production is associated with the commissioning of new, as well as the additional development of previously discovered fields. Current trends in the development of oil and gas drilling include an increase in the share of deep and superdeep, cluster and directional wells, due to enlarging the share of developed fields with deep hydrocarbons (Chen and Gao, 2018), (Zhan et al., 2016). The difficulty of drilling such wells is compensated by the increased efficiency of hydrocarbon recovery from them due to the increased contact area with the reservoir (Bouldin et al., 2014), (Eren and Suicmez, 2020).

Rotary steerable systems (RSS) are now widely accepted as a tool for complex directional well profiles. They have proven themselves especially well when drilling extended sections of the wellbore with a large offset from the vertical (Tribe et al., 2003), (Lines et al., 2012). It is mainly because already at the stage of oil-and-gas fields design and modelling of the wells, complex trajectories are created for opening remote objects, developing several deposits from one well, penetrating deep into the formation, and overcoming faults (Zhang et al., 2018), (Greenwood, 2018).

Global research and industry experience demonstrate the effective RSS use in unconventional oil (unconventional reservoir rock oil, such as shale) fields. Drilling of extended horizontal sections over the reservoir area in combination with various technologies for stimulation of oil recovery, in particular, hydraulic fracturing, allows both to increase the flow rate of a well in damped wells in fields with conventional oil, and to conduct profitable production of unconventional oil (Hummes, 2011), (Vilamova et al., 2016), (Fandi et al., 2018). Higher efficiency of RSS is observed in comparison with directional drilling done by downhole motors, using whipstock, curved subs, changing the position of stabilizers (Marck and Detournay, 2016), (Abdelsamad et al., 2018), (Wittenberger et al., 2012), due to the relative simplicity of horizontal drilling and azimuth control, minimum tripping operations and high quality of the wellbore, which directly determines the high rate of penetration (Fig. 1).
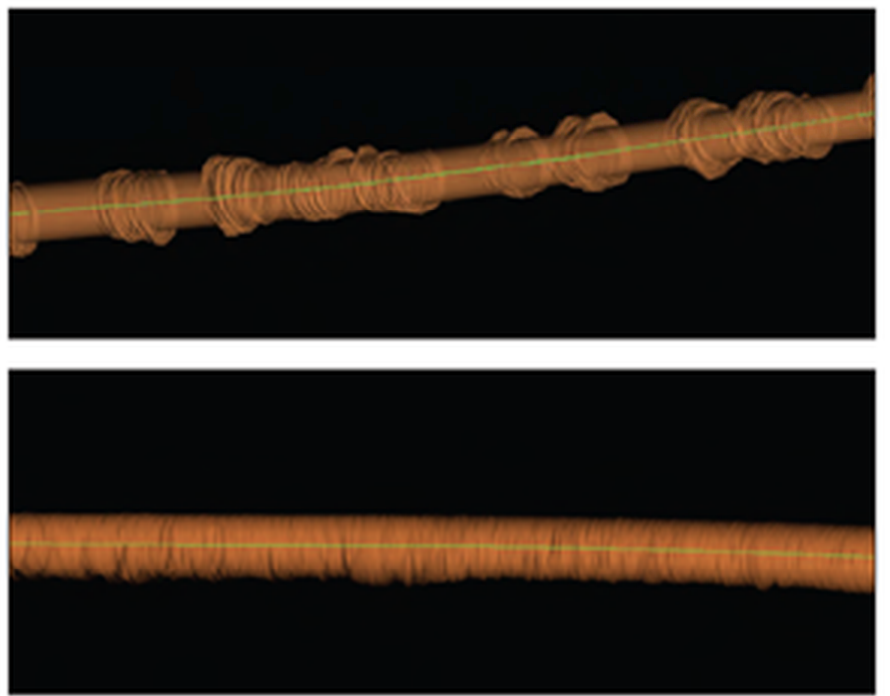

Fig. 1. Comparison of the wellbore quality built according to the calliper data: top - downhole motor with a bent sub, bottom - rotary steerable system.

The advantages of RSS over traditional equipment for directional and horizontal wells (higher drilling speed, rate of penetration, better cleaning of the well from drill cuttings, especially in horizontal sections, etc.) are associated with their high manufacturability and design complexity. An important advantage of RSS is the presence of the latest telemetry systems such as measurement while drilling (MWD) and logging while drilling (LWD) systems. Telemetry systems provide data on the directional survey (borehole trajectory), bottom-hole temperature, pressure, dynamic parameters of drilling and, in some cases, gamma-ray logging. LWD systems, on the other hand, provide data on the properties of rocks and formation fluids such as water, oil, gas, technically making it possible to abandon the traditional logging system in an open hole (Qutob and Kuchinski, 2010), (Kabirzadeh et al., 2018). In this case, LWD systems are always used in a single complex with the MWD telemetry system to actually calculate the trajectory of the drilled well. Push-the-bit and point-the-bit RSS use different control principles - depressing the steering pedals on the borehole wall and internal bending to deviate the drill string axis from the current borehole axis, respectively (Figueredo, 2014).

The use of these telemetry systems has a positive effect on the RSS reliability, as it provides drilling operators and engineers with information that allows them to judge the loads on the bottom-hole assembly 
(BHA). At the same time, there is an opinion (Stroud et al., 2011) that push-the-bit systems experience higher loads compared with point-the-bit systems because rejection is caused by the outer elements of the bottom hole assembly.

Despite the obvious advantages, one of the key factors preventing the widespread adoption of RSS is the high cost of these systems associated with their design features. This makes the issue of their reliability critical when choosing drilling equipment. Thus, the cost of renting an RSS per one meter of boring of a horizontal section of a wellbore may exceed the similar cost of renting a downhole motor with a telemetry system three or more times (Gaines, 2013). Given the inevitable risks associated with drilling a well, the drilling contractor often prefers to use the cheaper option, as the potential cost of a system failure or loss in the wellbore may outweigh the technological advantages of using RSS (Carpenter, 2014).

Discussion of the RSS advantages over the widespread traditional downhole motors touches on the area of system reliability. In the case of downhole motors, the latter depends on the risk of string sticking due to sliding along the recumbent borehole wall, uneven movement of the drilling mud around it, and reduced mud carrying capacity (Skalle and Aamodt, 2020), (Zhang et al., 2016).

RSS reliability studies are related to two application aspects in directional oil and gas drilling. The first aspect is technological, related to the exploitation of RSS (Guan et al., 2019), (Chamat and Isral, 2012), (Bykov and Tskhadaya, 2004). The second aspect is constructive, associated with the design features of the drilling equipment mechanism, the quality of its design, materials and workmanship, as well as maintainability and

servicing (Wang et al., 2014), (Brehme and Travis, 2008). Technological reliability factors include weight on bit, drill string rotation frequency, zenith angle, rock hardness and abrasiveness, etc. Kakharov S.K., Gandzhumyan R.A. related failures of drilling equipment with three groups of factors: partially dependent on the drilling crews (drilling mode, quality of drilling mud); independent of them (drilling depth, rock properties, climatic conditions, design features and quality of equipment) and completely dependent on the drilling crews (quality of maintenance and repair, drilling crew skills) (Kakharov and Gandzhumyan, 2013).

The constructive factors of RSS reliability relate to the stresses that the sliding elements of the mechanism are subjected to. For point-the-bit RSS, these elements are deflector elements, including anti-rotation levers, eccentric rings located inside the drill string's bottom. In the case of push-the-bit RSS, steering pedals that extend outward when the borehole zenith angle changes and experience maximum stress.

The influence of loads on the reliability of drilling equipment was studied by Reckmann H., Hohl A., Heinisch D., Stroud, D. (Reckmann et al., 2018), (Heinisch et al., 2016), (Hohl et al., 2015), (Stroud et al., 2011). At the same time, the issues of RSS reliability depending on loads in specific well conditions remain understudied. The exceptions are the works of Flegner P. Bowler A., Lentsch D., which are devoted to the problems of quality control of drilling using rotary systems, the influence of vibrations on the reliability of RSS, as well as problems of reliability of RSS when drilling deep geothermal wells (Flegner et al., 2015), (Bowler et al., 2014), (Lentsch et al., 2012).

Therefore, justifying the effect of loads on a push-the-bit rotary steerable system in the context of system reliability is relevant, especially for determining the possibilities of their control and its limits.

\section{Materials and Methods}

The research area is associated with the use of push-the-bit rotary steerable systems for drilling directional and horizontal wells, the bias unit of which is represented by pedals (Fig. 2). The examples of such systems are Schlumberger PowerDrive X5, X6; Halliburton iCruise, etc.

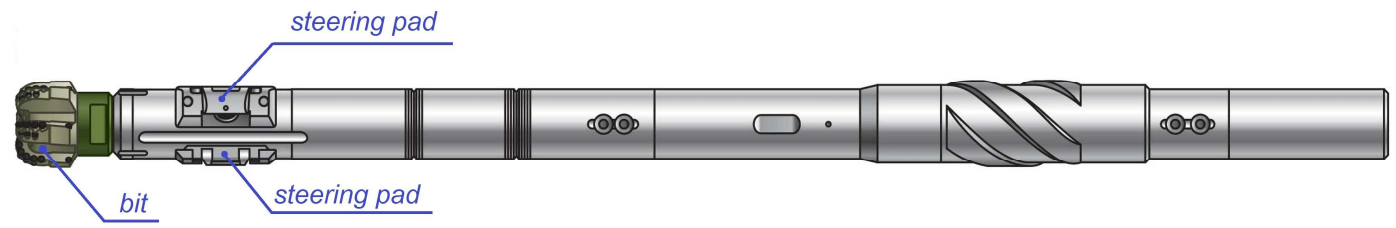

Fig. 2. Location of the steering pedals in the bottom-hole assembly of push-the-bit RSS (author's drawing, BHA image of push-the-bit RSS PowerDrive by Schlumberger (Schlumberger, 2017))

The study aims to evaluate the impact of steering pedal loads on the reliability of push-the-bit RSS. To calculate the loads on the steering pedals RSS, methods of theoretical mechanics were used, in particular, abstraction, vector calculus, which allow determining the parameters influencing the risk of system failure, such as the load on the steering pedals, bending stresses for the bottom of the bottom -hole assembly.

In the present paper, technological parameters were taken as the main parameters for calculating the loads on the steering pedals (change in zenith angle, weight on bit, the sequence of intensive sliding sections, wellbore depth, and the concentration of a lubricant additive in the drilling mud). Geological conditions (composition and 
rock hardness) were taken into account as common for all initial drilling parameters variations using push-the-bit RSS.

The reliability of RSS is the property of keeping within the established limits the values of all parameters characterizing the ability to perform their required functions in the given modes and conditions of use (Kozyreva, 2017). The violation of this RSS ability is a system failure. RSS reliability depends on the reliability of the articulated shaft rotating in the support nodes (Rusinov et al., 2017), the pedals of the bias unit (Novoseltsev et al., 2017), the pedal drive (Melekhin et al., 2018), as well as the quality of the drilling mud, drilling mode, and rock properties (Kakharov and Gandzhumyan, 2013).

In general, the set of main factors affecting RSS reliability and leading to failures of the bottom-hole assembly is presented in Table 1 (compiled by the authors).

Tab. 1. Overview of the main failure factors of RSS bottom-hole assembly

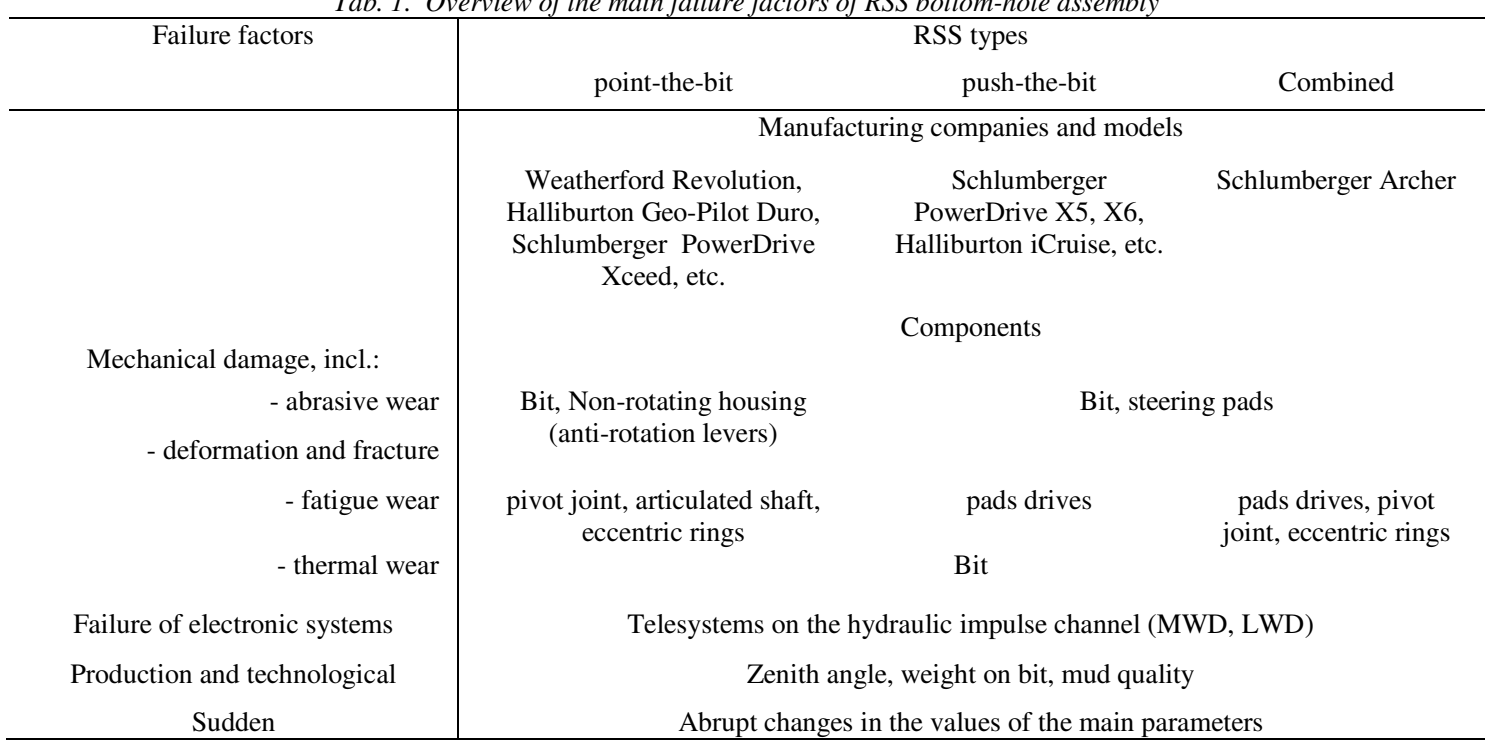

As shown in Tab. 1, most of the main BHA failure factors (electronic system failure, thermal wear, process parameters) are common to all RSS types. Factors specific to each RSS type (abrasive and fatigue wear, deformation and fracture) are associated with the design features of the bias unit. At the same time, the loads on the pedals and their drives are typical for both push-the-bit systems and combined ones (for example, Schlumberger Archer). Point-the-bit systems can either have non-rotating housing with anti-rotation levers (Weatherford Revolution, etc.) or not have it (Schlumberger PowerDrive Xceed, etc.) (Bryant, 2019). Therefore, steering pads are one of the most specific elements of the bias unit in terms of the impact of multiaxial loads on them on the reliability of BHA.

RSS reliability is of particular importance for the Russian oil and gas industry since the country has one of the world's largest shale oil reserves (73 billion barrels (Bulin, 2013)), the development of which requires modern directional drilling systems (including horizontal). Despite the highest cost, the use of RSS provides the maximum technological potential for shale oil recovery. The high cost of such systems, in turn, puts forward special requirements for their reliability and minimization of failures.

The problem of eliminating failures of individual elements of the RSS can be solved by simulating the system's operation in a certain range of downhole conditions and drilling modes, including the parameters of borehole curvature, weight on bit, lubricating action of the drilling mud. We assume that the steering pads' load is related to the resulting reaction force (Fig. 3). 


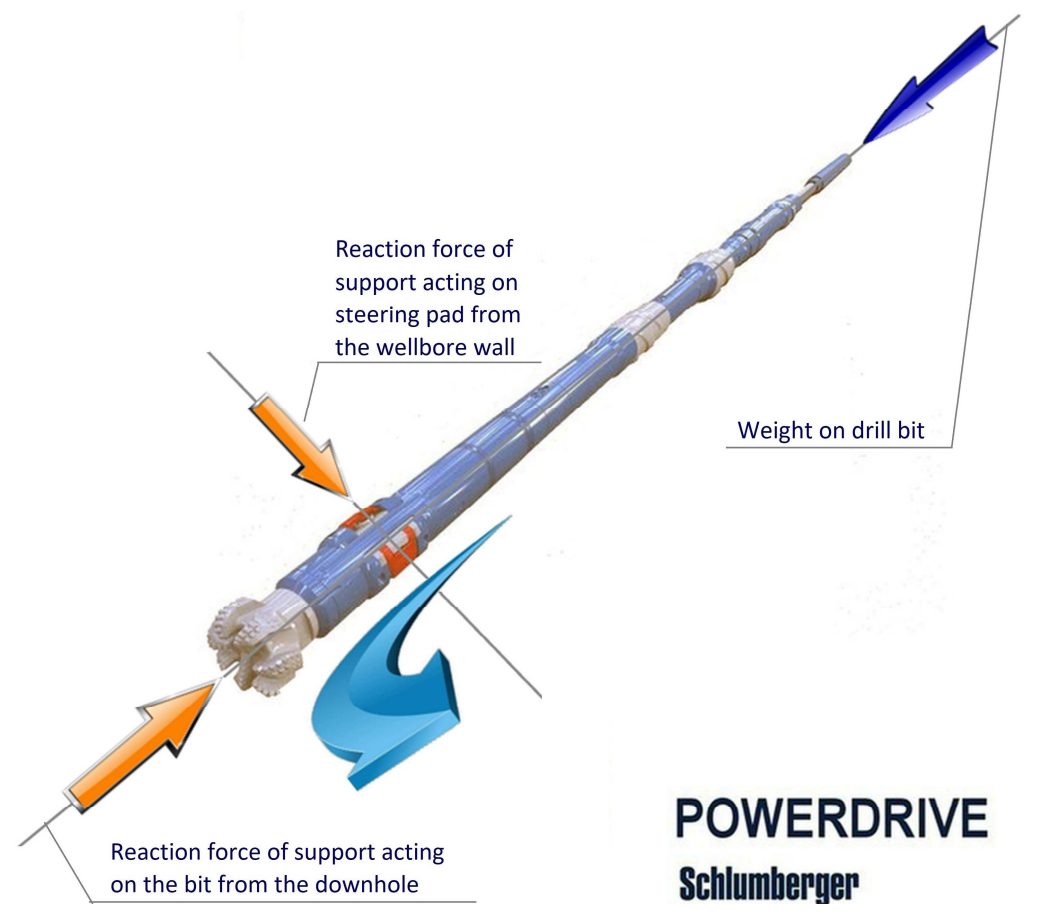

Fig. 3. Forces acting on the bottom-hole assembly of push-the-bit RSS (author's scheme, the image of BHA of push-the-bit RSS PowerDrive by Schlumberger (Schlumberger, 2017)).

Since the bias unit is a very vulnerable push-the-bit RSS module, it is necessary to calculate the load acting on its steering pads. For this, a rotary steerable system can be represented in the form of an absolutely elastic rod, for which the action of the drilling mud and rotation is taken into account in the form of a change in the friction force. Fig. 4 shows a schematic diagram of a simplified RSS model for a descending wellbore interval.

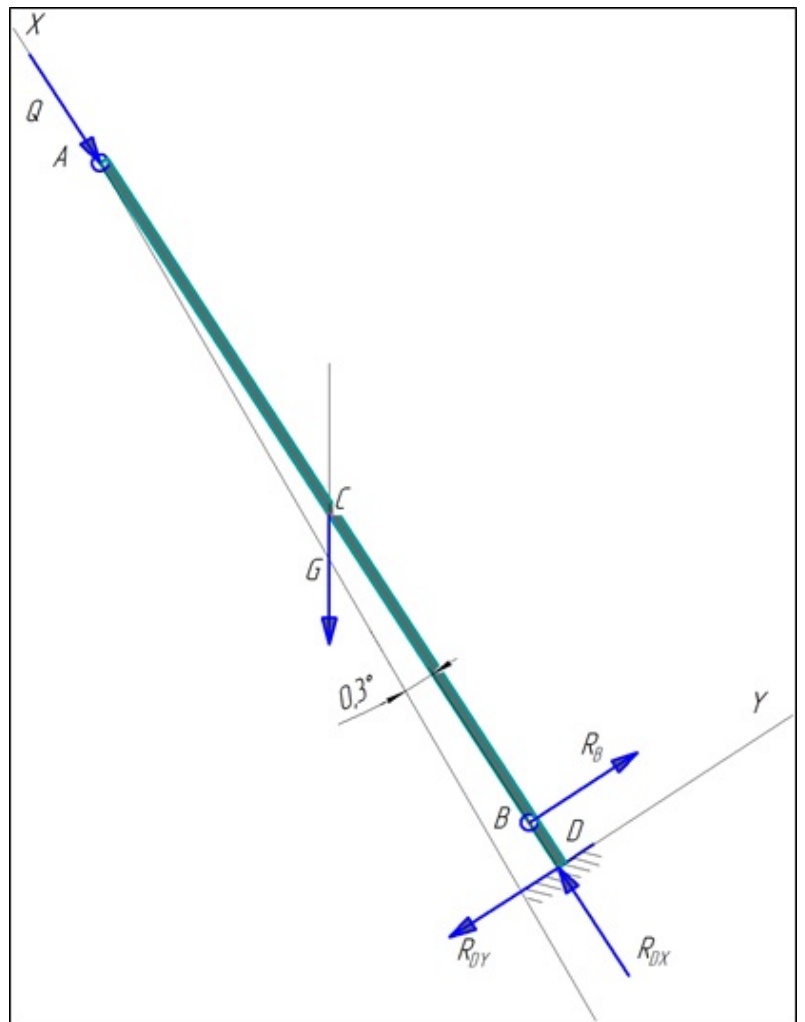

Fig. 4. Scheme of the RSS model on the interval of the descending wellbore, taking into account the forces acting on it

Weight on bit acting on the RSS is represented as a force $Q$ along the bar. The weight of the system itself is designated as the force $G$ applied in the middle of the rod (point $C$ ) vertically downward. The bottom-hole of 
the well is indicated by point $D$, the reaction force arising in it is presented in the form of two components $R_{D X}$ and $R_{D Y}$. The origin of the coordinate axes is at point $D$, the $\mathrm{X}$ and $\mathrm{Y}$ axes are directed along the components $R_{D X}$ and $R_{D Y}$ reaction forces. The steering pad is represented as support $B$, the resulting reaction $R_{B}$ is equal to the required load on the pedal, acting along the Y-axis. In this case, it is considered that the pedal is extended to the maximum distance $3 / 4$ inch, providing deviation $0,3^{\circ}$.

We compose the equations for the projections of the reaction force on the $\mathrm{X}$ and $\mathrm{Y}$ axes and the equation for the moments of force at point $D$ to find the reactions.

$$
\Sigma F_{X}=Q+G \times \cos \left(\theta+0.3^{\circ}\right)-R_{D X}=0
$$

where $F_{x}$ - the resultant of the projection on the $\mathrm{X}$-axis of the reaction forces at the point $D, \mathrm{kN}$; $Q$ - weight on bit acting on a rod (RSS), kN;

$G$ - weight of the rod (RSS), kN;

$\Theta$ - zenith angle, degrees;

$R_{D X}$ - axial component of the reaction force from bottom-hole directed along the axis $\mathrm{X}, \mathrm{kN}$.

$$
\Sigma F_{Y}=-G \times \sin \left(\theta+0.3^{\circ}\right)+R_{B}-R_{D Y}=0
$$

where $F_{y}-$ resultant of the projection on the $\mathrm{Y}$-axis of the reaction forces at the point $D, \mathrm{kN}$; $A D$ - rod length (RSS), m;

$R_{B}-$ rod reaction force (load on the pad), $\mathrm{kN}$;

$R_{D Y}$ - axial component of the reaction force from bottom-hole directed along the axis $\mathrm{Y}, \mathrm{kN}$.

$$
F_{M D}=-G \times \frac{A D}{2} \times \sin \left(\theta+0.3^{\circ}\right)+R_{B} \times B D=0
$$

where $F_{M D}-$ resultant moments at point $D, \mathrm{kNm}$;

$B D$ - distance from the steering pad to the bottom*hole, $\mathrm{M}$.

The forces that determine the load on the steering pad when the zenith angle is set can be expressed from the equations (2-3):

$$
\begin{gathered}
R_{D X}=Q+G \times \cos \left(\theta+0.3^{\circ}\right) \\
R_{B}=G \times \sin \left(\theta+0.3^{\circ}\right)+R_{D Y}=\frac{G \times \frac{A D}{2} \times \sin \left(\theta+0.3^{\circ}\right)}{B D}
\end{gathered}
$$

The calculation of the load was carried out with a step of changing the zenith angle of $1^{\circ}$, over the entire range of model applicability - from 0 to $89^{\circ}$. Based on the data obtained, the load's dependence on the technological parameters of drilling directional wells was received (Fig. 6).

With an increase in the zenith angle over $90^{\circ}$, the distribution of forces acting on the bottomhole assembly of RSS changes. The diagram of the model on the ascending interval is shown in Fig. 5.

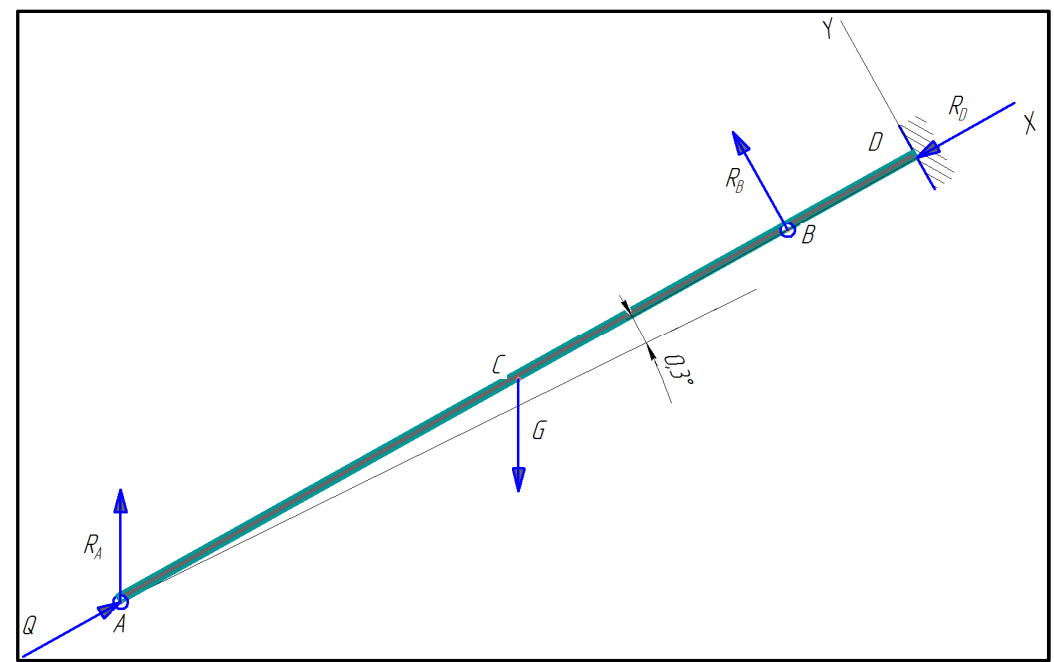

Fig. 5. Scheme of the RSS model on the interval of the ascending wellbore, taking into account the forces acting on it 
Due to the redistribution of the load, a reaction occurs $R_{A}$ in support $A$. At point $D$ the reaction $R_{D}$ directed in the longitudinal direction.

The equation of moments at point $A$ can be represented as follows:

$$
F_{M A}=G \times \frac{A D}{2} \times \sin \left(\theta+0.3^{\circ}\right)-R_{B} \times A B+R_{A Y} \times A D=0
$$

where $F_{M A}-$ resultant moments at point A, kNm;

$R_{A Y}$ - component of the borehole wall reaction force at point $A$, directed along the axis $\mathrm{Y}, \mathrm{kN}$.

Reaction $R_{A}$ in support $A$ must be taken into account when calculating the forces that determine the load on the steering pad when the zenith angle is set above $90^{\circ}$. Its dependence is obtained by transforming the equation (6):

$$
R_{A Y}=\frac{R_{B} \times A B}{A D}-\frac{1}{2} G \times \sin \left(\theta+0.3^{\circ}\right)
$$

The calculation of the load on the steering pad in the interval of the ascending wellbore was carried out with a similar step of changing the angle $\left(1^{0}\right)$, in the range $90-179^{\circ}$ (Fig. 7).

\section{Results}

As mentioned above, reducing the risk of push-the-bit RSS failure when drilling directional wells implies reducing the multiaxial loads on the elements of the bias unit, particularly on the pads (as being subjected to the greatest loads). The author's calculation of loads taking into account the acting forces was carried out for RSS Schlumberger PowerDrive X5 675 (diameter - 215.9-250.8 mm; BHA length - $4.11 \mathrm{~m}$; maximum curvature intensity, degrees / $30 \mathrm{~m}-6.5$; maximal weight on the bit $-800.68 \mathrm{kN}$, weight $-2463 \mathrm{~kg}$ ).

The performed calculation makes it possible to determine the nature of the increase in the loads when the technological parameters of drilling change as the maximum values are approached, directly determining the risk of system failure.

The results obtained made it possible to analyze the change in the design values of the loads with varying drilling parameters and compare them with the maximum values. The analysis of the obtained values made it possible to formulate recommendations for selecting optimal values of the concentration of the lubricating additive, based on the need to reduce the load on the deflecting module.

The calculated values of the load on the steering pads obtained using equations (1-7) for different intervals of the wellbore are shown in Fig. 6-7 (Fig. 6 - load on the descending interval, Fig. 7 - load on the ascending wellbore interval).

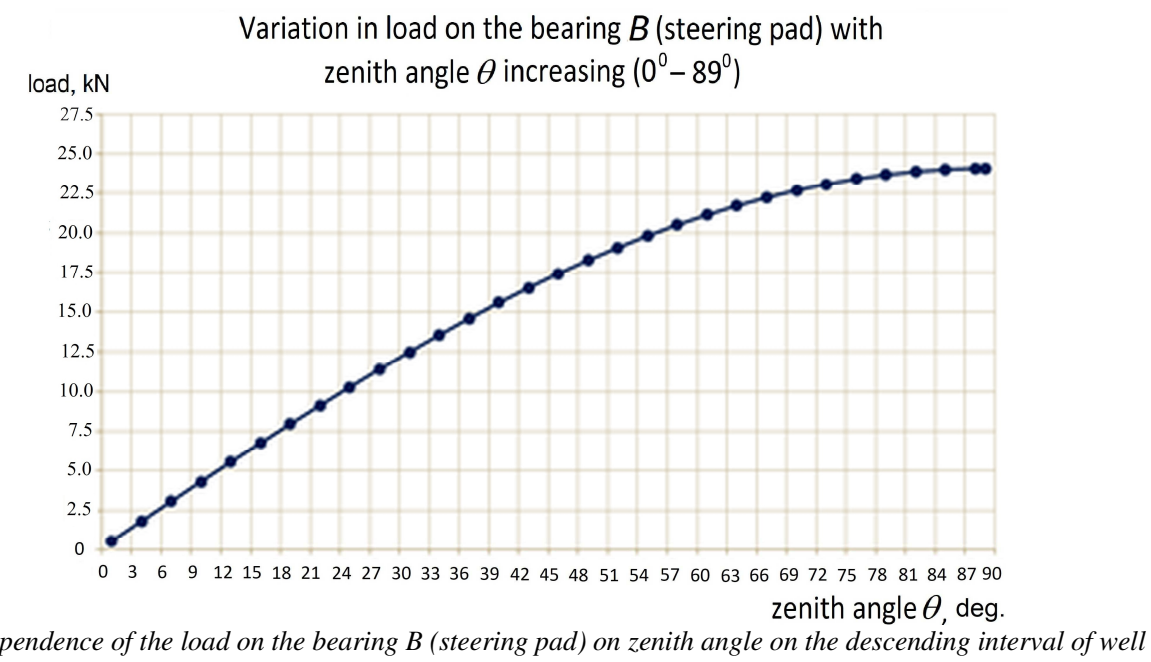

To take into account the influence of the weight on bit on the bias unit, it is assumed that for the shear of an object pressed against the surface, it is necessary to apply a force greater than or equal to the friction force. Thus, the final steering pad load of RSS is defined as the sum of the load calculated above and the frictional force. 


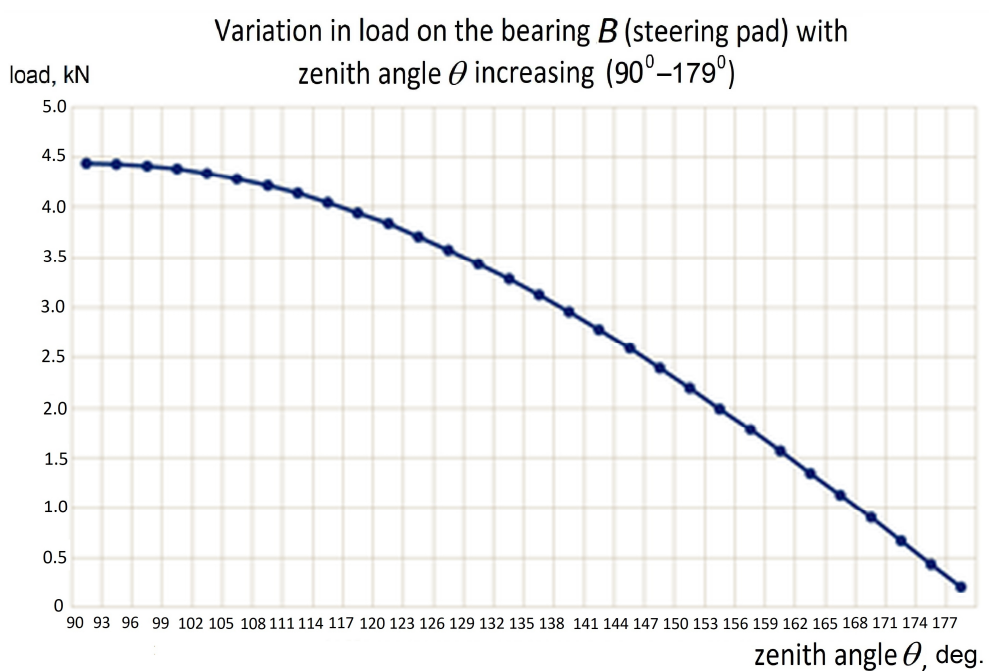

Fig. 7. Dependence of the load on the bearing B (steering pad) on zenith angle on the ascending interval of well

Observed in Fig. 6-7, multiple drops in the load on the steering pad occur during the construction of horizontal undulating sections of wells, in which the change in the zenith angle passes through the $90^{\circ}$ mark during the transition from ascending to descending intervals (Fig. 8).

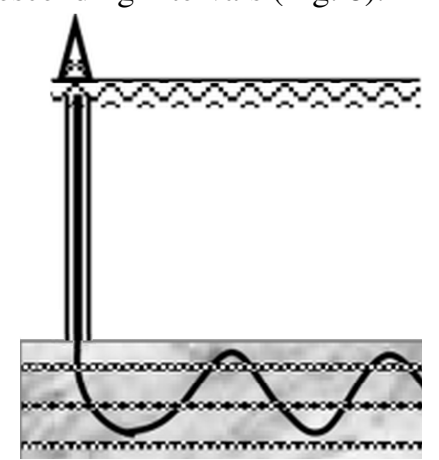

Fig. 8. Productive strata penetration by undulating well

Fig. 9 shows the calculation of the pad load at the weight on bit for the adopted drilling mode $(Q=60$ $\mathrm{kN})$ and for the maximum weight on bit for RSS Schlumberger PowerDrive X5 $675(Q=290 \mathrm{kN})$. Based on the data obtained, graphs of changes in the load on the steering pad were compiled depending on the weight's value on the bit for different intervals of drilling (Fig. 8).

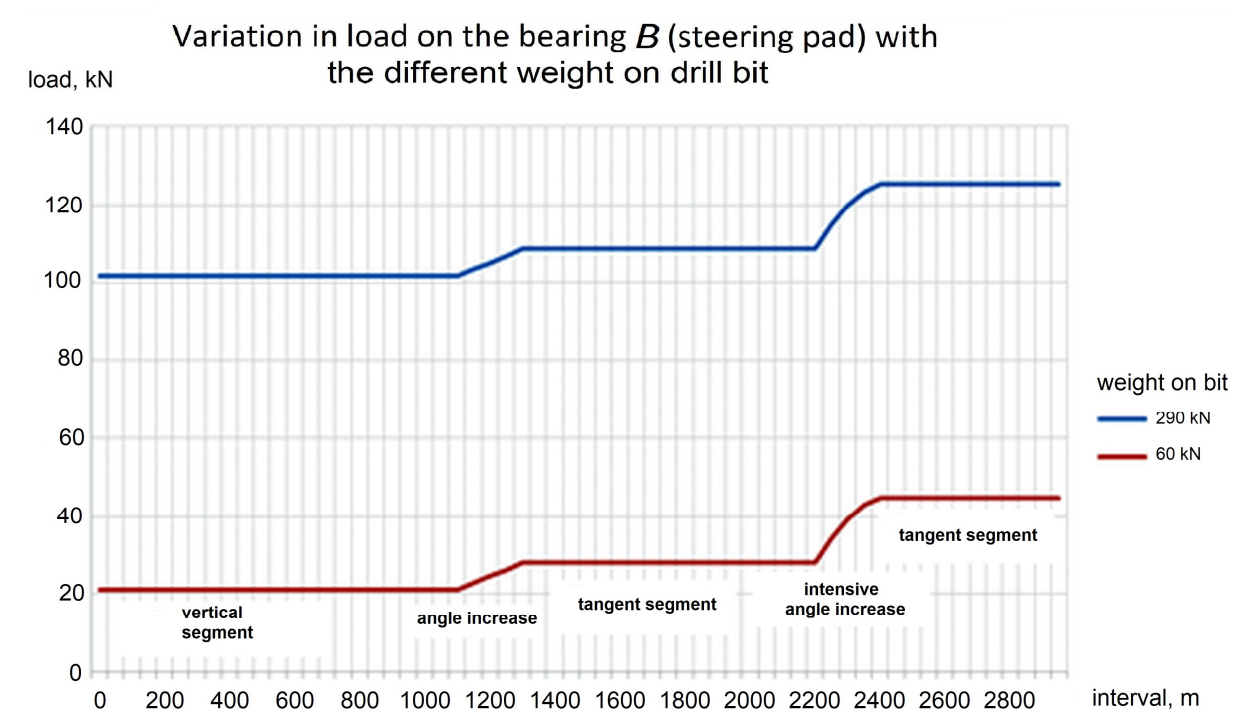

Fig. 9. Dependence of the load on the steering pad of RSS on the value of the weight on the bit at certain zenith angles 
In the course of experimental verification of the results obtained, the bending stresses of the drill string were calculated for a simulated well with a horizontal section using an independent method (using the "Drilling design" software 12.8, "BurSoftProject", (BurSoftProject, 2020)). The well depth was taken to be $3443 \mathrm{~m}$ along the borehole, the length of the horizontal section was $250 \mathrm{~m}$, and the maximum zenith angle was $85^{\circ}$. The measurement was carried out for the horizontal section with a change in the weight on a bit from 60 to $200 \mathrm{kN}$, with a step of $10 \mathrm{kN}$. Fig. 10 shows a graph of the bending stress for the bottom of the bottom-hole assembly with weight on a bit of $80 \mathrm{kN}$.

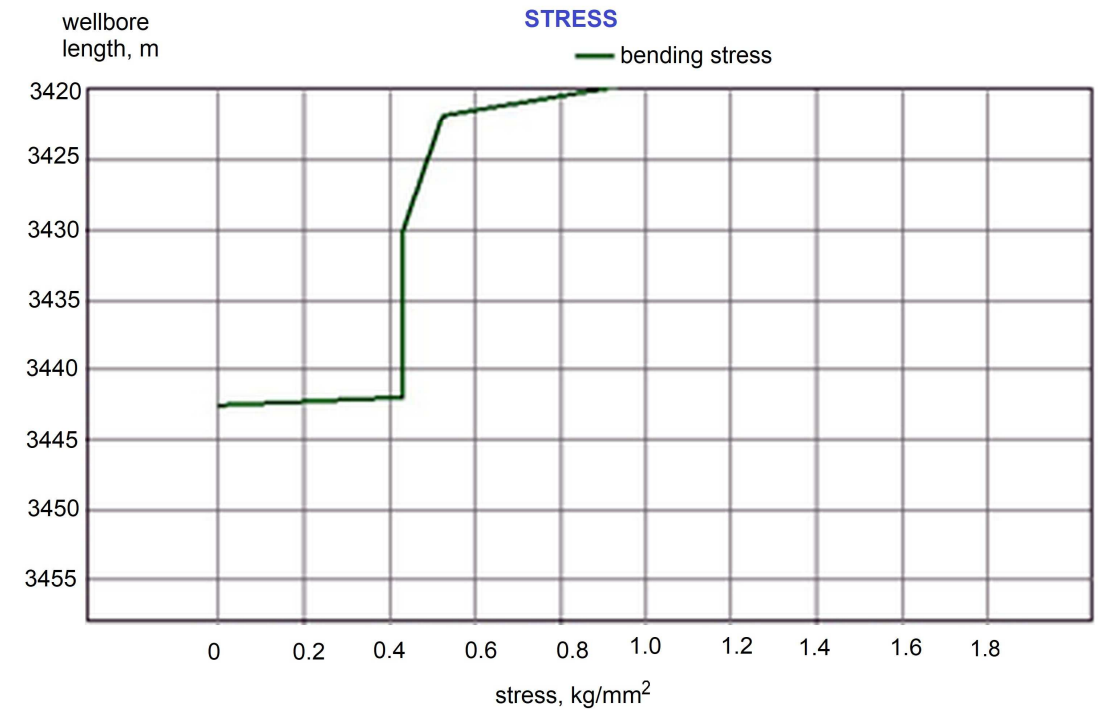

Fig. 10. Bending stress graph for the bottom of the bottom-hole assembly at the weight on bit of $80 \mathrm{kN}$

The bending stress at the bottom of the bottom-hole assembly, equal to $0.9 \mathrm{~kg} / \mathrm{mm}^{2}$, is equivalent to a steering pad load of $57.5 \mathrm{kN}$ (taking into account the pad surface area), which generally corresponds to the calculated data reflected in Fig. 9.

To take into account the friction force in the conditions of the projected well, the weighted average coefficient of steel friction against the rock is taken, considering the lubricating effect of the drilling mud (kav = 0.35). In our calculations, we used the "LUBRIOL" reagent - a lubricating additive for drilling muds (the manufacturer's recommended concentration is $0.4-1.2 \%$, the ability to reduce the coefficient of friction - to 0.04). The calculation of the load on the steering pad with a varying value of the friction coefficient, depending on the concentration of the lubricant in the drilling mud, is presented in Tab. 2. We used the parameters of the bottom-hole assembly of RSS Schlumberger PowerDrive X5 675 of the horizontal section (with the maximum frictional force), the reagent - lubricating additive "LUBRIOL". The calculation was carried out with a change in the additive concentration in the range of values recommended by the manufacturer, with a step of $0.2 \%$.

Tab. 2. Calculation of the load on the steering pad at various concentrations of the lubricant additive

\begin{tabular}{c|cccc}
\hline $\begin{array}{c}\text { Concentration } \\
{[\%]}\end{array}$ & Coefficient of friction & $\begin{array}{c}\text { Friction force } \\
{[\mathrm{kN}]}\end{array}$ & $\begin{array}{c}\text { Zenith angle } \theta \\
{[\mathrm{deg}]}\end{array}$ & $\begin{array}{c}\text { Steering pad load } \\
{[\mathrm{kN}]}\end{array}$ \\
\hline 0.40 & 0.25 & 20.00 & 85.00 & 44.03 \\
0.60 & 0.19 & 15.20 & 85.00 & 39.23 \\
0.80 & 0.14 & 11.20 & 85.00 & 35.23 \\
1.00 & 0.08 & 6.40 & 85.00 & 30.43 \\
1.20 & 0.04 & 3.20 & 85.00 & 27.23 \\
\hline
\end{tabular}

\section{Discussion}

Having analyzed the obtained values of the calculations of the load on the steering pads of the bottom-hole assembly of RSS Schlumberger PowerDrive X5 675, the following regularities were determined, which make it possible to judge the influence of the technological parameters of drilling on the reliability of the system.

Firstly, a polynomial dependence of the second degree is observed for the section of the angle gain (Fig. 6). Moreover, if we analyze the load when the zenith angle is set to $30^{\circ}$, there is a direct proportionality between the applied weight on the bit on the tool and the instantaneous load on the steering pads; then the increase in the load on them slows down. This is due to an increase in the effort to overcome the resistance forces from the side of the borehole since we state that at a zenith angle of up to $30^{\circ}$, the roughness of the borehole walls and the angle 
of inclination of the wellbore have an uncritical effect on the increase in friction forces. When the zenith angle exceeds the critical value of $30^{\circ}$, the effect of friction forces increases sharply.

In contrast, for the ascending section of the well (Fig. 7), there is a decrease in pad's load with an increase in the zenith angle. This is due to the following physical phenomenon. In the interval with ascending sections, the phenomenon of "well with negative weight" is observed, that is, a well in which the friction forces are so high that it is impossible to run the tool under its own weight. That is, there will be a need to create additional "pushing" weight on the bit on the tool. Consequently, compared with the situation with the angle set from $0^{0}$ to $90^{\circ}$, there is a decrease in the loads on the steering pads RSS because the load simply does not reach them, since it is distributed to overcome the friction forces. In addition, in sections with an inclination angle of more than $90^{\circ}$, a decrease in load is observed due to the fact that the gravity vector of the tool's own weight is directed in the opposite direction relative to the weight on bit vector (Fig. 5). Thus, if the weight of RSS and the weight on the bit are close in magnitude, then during the drilling of the upwelling section of the well (the zenith angle is close to $180^{\circ}$ ), a situation of hovering of the tool may occur - when the weight on bit and gravity force vectors are directed in opposite directions along one straight line. At the same time, it is important that the section of the tool through which the weight on bit is transmitted is absolutely rigid in order to exclude the possibility of redistribution of the applied force on the borehole walls due to bending.

Secondly, comparing the graphs in Fig. 6 and 7, one can see that at the transition point of the zenith angle of $90^{\circ}$ (horizontal bore), there is a sharp drop in the load on the steering pad - more than five times. Based on this, we can make a preliminary conclusion about the danger of using push-the-bit RSS when posting undulating horizontal profiles (Fig. 8), where the given point is repeatedly crossed, as this can cause negative fatigue loads on the RSS elements. Also, the above-considered action of friction and gravity forces in the zenith angle interval of $90-180^{\circ}$, all other things being equal, reduces the efficiency of RSS work on borehole curvature. Therefore, when drilling undulating profiles, it is necessary to change the drilling mode - to vary the weight on bit and rotational speeds.

From the data in Fig. 9, the decisive role of the weight on the bit in the formation of the force acting on the steering pads follows, therefore, in the areas of intense curvature, a change in the drilling mode creates a significant increase in loads that can approach the maximum. This is due to an increase in the support reaction force with an increase in the zenith angle. Therefore, in severe curvature areas, care should be taken to reduce the risk of system failure. Fig. 10 shows the confirmation of the author's calculation method by an independent method, in which the bending stresses for the bottom of the bottom-hole assembly correspond to the given data on the loads on the deflecting pedals.

Thirdly, presented in Tab. 2 the assessment results of the effect of lubricating additive concentration in the composition of the drilling mud confirmed the expectations, which were expressed in the reduction of the calculated values of the loads on the steering pads RSS. At the same time, it should be borne in mind that in the practice of drilling it is difficult to justify and implement an increase in the amount of a lubricating additive in the composition of the drilling mud for two reasons. The first is an increase in the cost of drilling mud service while drilling contractors seek to reduce the cost of well construction. The second reason is the need to completely revise or adjust the flushing program due to changes in the properties of the drilling mud. It is possible that a change in the concentration of the lubricant in the composition of the drilling mud may lead to a deterioration in signal transmission between RSS and the surface of the earth, while the development of RSS, announced by Schlumberger, implies the continued use of the hydraulic pulse channel of bi-directional communications between surface systems and downhole tools. In addition, a decrease in the friction forces on the descending sections of the well trajectory can lead to a multiple increase in the loads on the steering pads RSS. Therefore, further research is needed on the effect of frictional forces on pad loads, in collaboration with lubricant manufacturers and oilfield service contractors.

Fourth, the results of calculations of the load on the steering pads presented in Fig. 6-7 and 9-10 are made for the depth of drilling oil and gas wells in the fields in the Russian Federation, far from the maximum value. The weight on a bit of $60-290 \mathrm{kN}$ is also not the limit for currently used and projected RSS, including Schlumberger PowerDrive family. Thus, at the maximum weight on a bit of $800 \mathrm{kN}$ (Schlumberger PowerDrive X6 675 (Schlumberger, 2017)), the load on the steering pads will reach, according to calculations, $345 \mathrm{kN}$. In the future, with the construction of deeper wells, the development of technologies and equipment for directional drilling, the requirements for its reliability increase. At the same time, the loads on the bias unit will increase, which, when approaching critical values will increase the risk of system failure and significantly reduce the RSS reliability. Therefore, further research is needed on the effect of push-the-bit steering pad loading on RSS reliability. This is especially important with the development of combined systems such as the Schlumberger Archer. At the same time, the connection of two types of bias units in such systems - point-the-bit and push-thebit - leads to a redistribution of the load between them. This, in turn, is both a limitation of the application of the method of calculating loads on the steering pads of the bias unit considered in the article and a prerequisite for its further study. 
Also, within the framework of the above analysis, the possible azimuthal curvature of the well trajectory was not taken into account, which, of course, would have made adjustments to the ratio of loads acting both on the RSS, in general, and on the steering pads. The second assumption made in the calculations was the elimination of vibration loads, which will also have an additional negative effect on the steering pads, as well as on their attachment points in the RSS housing. Suppose for the RSS and drilling modes used today; vibration loads are taken into account by manufacturers both in designs and in recommendations, then for the reliability of future systems designed for deeper drilling and more intensive sliding. In that case, the study of the effect of vibration on the deviating elements requires additional research.

\section{Conclusions}

The trend towards the depletion of developed conventional hydrocarbon reserves, as well as an increase in the depth of deposits and the discovery of unconventional oil and gas reserves that are promising for development in the near future, leads to the drilling of deeper wells with a large proportion of directional and horizontal wells. As a result, state-of-the-art drilling equipment - rotary steerable systems - is constantly evolving. When drilling undulating horizontal well profiles, there are sharp drops in the load on the steering pads of the RSS, which puts forward additional requirements for the reliability of such systems, especially future ones - more expensive ones designed for operation in more severe conditions and drilling modes.

The loads on the bias unit push-the-bit RSS (steering pads) considered in the article were analyzed by the example of widely used model Schlumberger PowerDrive X5 675, presented in the form of an absolutely elastic rod, for two intervals of the zenith angle- $0-90^{\circ}$ and $90-180^{\circ}$, as well as operating and weight on bit limit values. In the article, steering pad loads were considered as a specific failure factor of push-the-bit systems and a significant factor for combined RSS (Schlumberger Archer, etc.), directly determining their reliability.

The calculations showed that the increase in the load on the deflecting pedal occurs linearly in the zenith angle range of $0-30^{\circ}$, then up to $90^{\circ}-$ decreasing. The greatest difference in pedal loads occurs during the transition from ascending to the descending interval of the borehole - by 5 times, which reduces the reliability of the push-the-bit RSS when drilling horizontal undulating wells. In the course of the study, a direct relationship was established between the weight on bit and the load on the steering pad, which indicates the need for further studies of the effect of fatigue deformations on the reliability of RSS as the depth of the wells and the number of undulating sections increase. In addition, when drilling undulating profiles, it is recommended to adjust the drilling mode to avoid the values of loads on the steering pads, which are close to the maximum.

The study investigated the possibility of reducing the load on the steering pads by increasing the concentration of the lubricant in the drilling mud. The calculations have shown that a threefold increase in the concentration of the lubricating additive causes a 1.6 times decrease in the load on the steering pads, all other things being equal. However, the use of drilling mud for signal transmission between RSS and the surface in modern systems, as well as for flushing a well, makes it difficult to change its composition without additional studies in adjacent areas. Therefore, at the moment we consider this way of reducing the loads on the steering pad of push-the-bit RSS rather as a theoretical one. In general, the development of the proposed method for assessing and reducing the loads on the bias unit of RSS will also be supplemented by studies of the effect of azimuthal curvature of the well trajectory and vibration loads on its reliability. This is of high importance for the analysis of the load on combined RSS (Schlumberger Archer, etc.), in which, due to the combination of deflecting systems (pivot joint and steering pads), the intensity of the zenith angle is higher. The approach proposed in the article is suitable for finding the specific arear of the downhole, where the load on the pads are maximal, however, for a more accurate calculation of them for combined RSS, it is necessary to take into account the redistribution of loads between pivot joint and steering pads. It determines the direction of future research in this area.

\section{References}

Abdelsamad, H., Muir, D., Ibrahim, A., Mansour, M., Osman, A., Rafik, A. and Remah, M. (2018). Middle East First Introduction of MWD and RSS Systems Below Mud Motor Mitigates Vibrations in Harsh Drilling Environment and Delivers a Record Well in Egypt Western Desert Khalda Operations. Offshore Technology Conference Asia, 20-23 March 2018, Kuala Lumpur, Malaysia, pp. 13

Bouldin, B., Verma, C., Bellaci, I., Black, M., Dyer, S., Algeroy, J., and Pan, Y. (2014). Prototype Test of an All-Electric Intelligent-Completion System for Extreme-Reservoir-Contact Wells.SPE Drilling \& Completion. 29(3), pp. 10 doi:10.2118/166507-PA

Bowler, A. I., Logesparan, L., Sugiura, J., Jeffryes, B. P., Harmer, R. J., and Ignova, M. (2014). Continuous High-Frequency Measurements of the Drilling Process Provide New Insights into Drilling System 
Response and Transitions between Vibration Modes. SPE Annual Technical Conference and Exhibition, 27-29 October 2014, Amsterdam, The Netherlands, 3, pp. 1859-1874 doi:10.2118/170713-MS

Brehme, J. and Travis, T. (2008). Total BHA Reliability - An Improved Method to Measure Success. IADC/SPE Drilling Conference, 4-6 March 2008, Orlando, USA, 2, pp. 769-778 doi:10.2118/112644-MS

Bryant T. (2019). An Operational Comparison of push-the-bit Rotary Steerable Tools. APS Technology Inc. URL: https://www.aps-tech.com/site/assets/files/1/aps_rss-white-paper.pdf

Bykov, I.Y. and Tskhadaya, N. D. (2004). Operational reliability and efficiency of drilling machines: Textbook (Ukhta: USTU, 194 p.) (in Russian)

Bulin, D. (2013). Russia does not know what to do with the sea of shale oil. BBC. 11 June 2013 (in Russian). URL: https://www.bbc.com/russian/business/2013/06/130611_shale_oil_russia

Official Web Site of BurSoftProject Ltd (in Russian), 2020. URL: http://www.burproject.ru

Carpenter, C. (2014). Rotary-Steerable Tool Brings Cost-Effective Performance to High-Volume Drilling. Journal of Petroleum Technology. 66(12), pp. 3 doi:10.2118/1214-0111-JPT

Chamat, E. and Isral, R. (2012). Efficient and Reliable Vertical Drilling of Top Holes with RSS in Deepwater GOM. IADC/SPE Drilling Conference and Exhibition, 6-8 March 2012, San Diego, California, USA. 2, pp. 863-876 doi:10.2118/151395-MS

Chen, X., and Gao, D. (2018). The Maximum-Allowable Well Depth While Performing Ultra-Extended-Reach Drilling From Shallow Water to Deepwater Target. SPE Journal. 23(1), pp. 13 doi:10.2118/183025-PA

Eren, T. and Suicmez, V. (2020). Directional drilling positioning calculations. Journal of Natural Gas Science and Engineering, 73, pp. 103081 https://doi.org/10.1016/j.jngse.2019.103081.

Fandi E. I. M., Leković B., Gazal B., Elhaddad E., and Al Saghr A. (2018). Implemented stage fracturing technique to improve oil production in Nubian sandstone of North Gialo, Libya. Acta Montanistica Slovaca. 23(3), pp. 245-259

Figueredo, C. (2014). Enhanced RSS Technology Pushes Drilling Envelope.

Journal of Petroleum Technology. 66(3), pp. 3 doi:10.2118/0314-0032-JPT

Flegner P., Feriančiková K., Lazarová E. and LeššoI. (2015). Some problems in control of the quality of the process of rotary drilling of rocks by using suitable visualization of concurrent vibrations. Acta Montanistica Slovaca. 20(4), pp. 282-289

Gaines, M. J., Neil, P. and Herrington, D. (2013). Novel Drilling System Offers Rotary Steerable System Performance with Real Time Survey in Top Hole Sections While Reducing Overall Costs. SPE Annual Technical Conference and Exhibition, 30 September-2 October 2013, New Orleans, Louisiana, USA. 6, pp. 4539-4546 doi:10.2118/166467-MS

Greenwood, J. A. (2018). Directional Control and Rathole Elimination While Underreaming Depleted Formations With a Rotary-Steerable System. SPE Drilling \& Completion. 33(3), pp. 7 doi:10.2118/187098-PA

Guan, Z.C., Wang, H., Shi, Y.C., Chen, W.Q., Zhao, G.S., Wang, J.-Y. and Cao, G.-Q. (2019). Dynamic behavior analysis of push-the-bit rotary steerable bottom hole assembly. Journal of Mechanical Science and Technology. 33(4), pp. 1501-1511 doi:10.1007/s12206-019-0302-5

Heinisch, D., Oueslati, H., Popp, T. M., Meyer-Heye, B., Schepelmann, C. and Reckmann, H. (2016). Testing and Characterization of Shock and Vibration Loads to Enhance Drilling Tool Reliability and Efficiency.

Abu Dhabi International Petroleum Exhibition \& Conference, 7-10 November 2016, Abu Dhabi, UAE, pp. 25 doi:10.2118/183037-MS

Hohl, A., Tergeist, M., Oueslati, H., Jain, J.R., Herbig, C., Ostermeyer, G.-P. and Reckmann, H. (2015). Derivation and experimental validation of an analytical criterion for the identification of self-excited modes in drilling systems. Journal of Sound and Vibration. 342, pp. 290-302. doi: 10.1016/j.jsv.2015.01.002

Hummes, O., Janwadkar, S. S., Powers, J. R., Bond, P. R., Anderson, M. E., Chesher, S. W. and Hildebrand, J. D. (2011). Evolution of High Build-Rate RSS Changes the Approach to Unconventional Oil and Gas Drilling. SPE Annual Technical Conference and Exhibition, 30 October-2 November 2011, Denver, USA. 6, pp. 4543-4551 doi:10.2118/147455-MS

Kabirzadeh, H., Rangelova, E., Lee, G. H., Jeong, J., Woo, I., Zhang, Y. and Kim, J. W. (2018). Dynamic Error Analysis of Measurement While Drilling Using Variable Geomagnetic In-Field Referencing. SPE Journal. 23(6), pp. 12 doi:10.2118/188653-PA

Kakharov, S.K. and Gandzhumyan, R.A. (2013). Reasons for failure of drilling equipment during operation. Oil engineer. 2, pp. 32-33 (In Russian).

Kozyreva, S.V. (2017). Operation and repair of oil and gas field equipment: Textbook (Gomel: P.O. Sukhoi GSTU, 178 p.)

Lentsch D., Savvatis A., Schubert A. and Schoebel W. (2012). Overcoming Drilling Challenges With Rotary Steerable Technology in Deep Geothermal Wells in the Molasse Basin of Southern Germany. GRC Transactions. 36(1), 96567 pp. $165-169$ 
Lines, L. A., Stroud, D. R. H., Minett-Smith, D. J. and Pagett, J. (2012). Unique analytical model improves understanding of violent dynamic behaviour of advanced oilfield rotary steerable drilling systems. 10th International Conference on Vibrations in Rotating Machinery, 11-13 September 2012, London, UK, pp. 591-600 https://doi.org/10.1533/9780857094537.9.591

Marck, J. and Detournay, E. (2016, February 1). Influence of Rotary-Steerable-System Design on Borehole Spiraling. SPE Journal. 21(1), pp. 10 doi:10.2118/174554-PA

Melekhin A.A., Turbakov M.S., Rusinov D.Yu., Chernyshov S.E. and Zlobin A.A. (2018). Block of deviation of the drilling device control system. Russian Federation Patent, RU2655325C1, 25.05.2018.

Novoseltsev D.I., Epikhin A.V., Anisimov A.V. (2017). Application of the methodology for calculating loads acting on the deflecting module of a rotary controlled system to determine the risk of system failure. Onshore and offshore oil and gas well construction. 6, pp. 4-8 (In Russian).

Qutob, H. H., and Kuchinski, R. (2010). New generation of MWD, LWD and image Logging Opens New Possibilities For Data Acquisition And Evaluation In Deep Gas Reservoirs.

SPE Deep Gas Conference and Exhibition, 24-26 January 2010, Manama, Bahrain, pp. 590-596 doi:10.2118/132157-MS

Reckmann, H., Hohl, A., Oueslati, H., and Akimov, O. (2018). Step Change in BHA Reliability and Performance Due to Utilization of Downhole Drilling Dynamics Services. IADC/SPE Asia Pacific Drilling Technology Conference and Exhibition. 27-29 August 2018, Bangkok, Thailand, 1, pp. 885-903 doi:10.2118/191096-MS

Rusinov, D. I., Turbakov, M. S., Kunitskikh, A. A. and Krysin, N. I. (2017, December 1). Study of the reliability of the drilling control system's deflection unit. Oil Industry Journal. 2017(1), pp. 4 (In Russian)

Skalle, P. and Aamodt, A. (2020). Downhole failures revealed through ontology engineering. Journal of Petroleum Science and Engineering. 191, 107188 doi: 10.1016/j.petrol.2020.107188

Schlumberger PowerDrive X6. Rotary Steerable System, 2017. URL: https://www.slb.com//media/files/drilling/product-sheet/powerdrive-x6-ps.ashx

Stroud, D., Pagett, J. and Minett-Smith, D. (2011). Real-time whirl detector improves RSS reliability, drilling efficiency. Hart's $E$ and P. AUGUST, pp. 14

Tribe, I. R., Burns, L., Howell, P. D., and Dickson, R. (2003, March 1). Precise Well Placement With Rotary Steerable Systems and Logging-While-Drilling Measurements. SPE Drilling \& Completion. 18(1), pp. 8 doi:10.2118/82361-PA

Vilamová Š., Piecha M. and Pavelek Z. (2016). Unconventional oil resources exploitation: A review. Acta Montanistica Slovaca. 21(3), pp. 247-257

Wang, R., Xue, Q., Han, L., Sun, F. and Yue, W. (2014). Torsional vibration analysis of push-the-bit rotary steerable drilling system. Meccanica. 49(7), pp. 1601-1615 doi: 10.1007/s11012-014-9942-9

Wittenberger G., Cehlár M. and Jurkasová Z. (2012). Deep hole drilling modern disintegration technologies in process of HDR technology. Acta Montanistica Slovaca. 17(4), pp. 241-246

Zhan, H., Wang, J., Zhao, K. Lu, H., Jin, K., He, L., Yang, G. and Xiao, L. (2016). Real-time detection of dielectric anisotropy or isotropy in unconventional oil-gas reservoir rocks supported by the obliqueincidence reflectivity difference technique. Scientific reports. 6, pp. 39306 https://doi.org/10.1038/srep39306

Zhang, C., Zou, W. and Cheng, N. (2016). Overview of rotary steerable system and its control methods. 2016 IEEE International Conference on Mechatronics and Automation, Harbin, 2016, pp. 1559-1565, doi: 10.1109/ICMA.2016.7558796

Zhang, C., Zou, W., Cheng, N. and Gao. J. (2018). Trajectory tracking control for rotary steerable systems using interval type-2 fuzzy logic and reinforcement learning. Journal of the Franklin Institute. 355(2), pp. 803826 https://doi.org/10.1016/j.jfranklin.2017.12.001 